\title{
Population prevalence of asthma and its determinants based on European Community Respiratory Health Survey in the United Arab Emirates
}

\author{
Bassam H Mahboub ${ }^{1}$, Suleiman Al-Hammadi ${ }^{*}$, Mohamed Rafique ${ }^{1}$, Nabil Sulaiman ${ }^{3}$, Ruby Pawankar ${ }^{4}$, \\ Abdulla I Al Redha ${ }^{5}$ and Atul C Mehta ${ }^{6}$
}

\begin{abstract}
Background: No population study has explored the population distribution of adult asthma in the United Arab Emirates (UAE). The objective is to estimate asthma prevalence in general population in UAE.

Methods: Using standard European Community Respiratory Health Survey (ECRHS) questionnaires and tools, this is a cross-sectional assessment of a random sample of the population in established quotas of the seven Emirates in the UAE. We surveyed 1,220 participants, of which $63.2 \%$ were male, and 20.1\% were UAE Nationals, with a mean (SD) age of 32.9 (14.1) years.

Results: Prevalence of individual respiratory symptoms from the ECRHS screening questionnaire in all participants were generally ranging $8-10 \%$, while participants 20-44 years presented lower prevalence in all symptoms $(p<$ 0.05). The expected male:female ratio of reported wheezing and asthma attacks and its treatment by age was not observed. Participating women reported more individual symptoms than men. Overall, there were 15.4\% (95\% C.I. 13.5 - 17.5) participants who fulfilled our screening criteria for asthma, while for consistency with ECRHS, there were 12.1\% (95\% C.I. 10.4 - 14.1) participants who fulfilled the ECRHS asthma definition, being 9.8\% (95\% C.I. 7.8 12.2) of those $20-44$ years, that is $8.6 \%$ of male and $11.8 \%$ of female young adults participating.

Conclusion: We conclude that asthma is common in the UAE, and gender differences are not observed in reported asthma symptoms in young adults. This being the first population based study exploring the prevalence of asthma and its determinants in the United Arab Emirates based on the ECRHS.
\end{abstract}

\section{Background}

Asthma is a complex, chronic disease that can manifest at any age [1-3]. It has a very heterogeneous distribution, and its prevalence has been increasing in all regions of the World, likely due to a combination of factors, and many unknowns remain in determining asthma causation [4]. The disease represents a significant burden, not only in terms of morbidity and reduced quality of life of patients, but also in terms of healthcare cost $[5,6]$.

\footnotetext{
* Correspondence: suleiman.alhammadi@uaeu.ac.ae

${ }^{2}$ Department of Pediatrics, Faculty of Medicine and Health Sciences, UAE

University, P.O.Box 17666 Al-Ain, United Arab Emirates

Full list of author information is available at the end of the article
}

Two international surveys of asthma prevalence have greatly enhanced our knowledge of the distribution and risk factors of asthma worldwide. First, the International Study of Asthma and Allergies in Childhood (ISAAC) [7], conducted in children of 6-7 and 13-14 years. Later, the European Community Respiratory Health Survey (ECRHS) [8], surveying that 20-44 years old, also led to an increased understanding of the worldwide distribution of asthma in young adults. Whilst Western Europe has some of the highest prevalence rates of asthma in the World, the ISAAC study found that the prevalence is not only high in English-speaking countries like the UK, Australia, New Zealand, and the US, but also identified new hot spots with higher than expected asthma in

\section{Biomed Central}


participating centers in other countries in Latin America, Asia, and elsewhere [9]. There is a scarcity of data about the distribution of asthma in the Gulf and near. Although studies have been carried out, they involved relatively small samples of patients selected from a limited number of clinical or other institutional settings, and latest data is not available. In UAE, in particular, there was an ISAAC asthma center, which reported a prevalence of physiciandiagnosed asthma of $13 \%$ in 3,200 children aged 6-13 years in the seven Emirates of the UAE [10]. There have been other small studies surveying asthmatic children. However, to our knowledge no population study has explored the population distribution of adult asthma in the UAE. By using the screening questionnaire and tools of the ECRHS, we aimed to determine the prevalence of asthma symptoms in the general population in the UAE.

\section{Methods}

This is a cross-sectional assessment of a random sample of the population of the UAE. The UAE lies within the Arabian Gulf Region, with seven Emirates, namely Abu Dhabi, Dubai, Sharjah, Ajman, Umm Al-Quwain, Ras Al-Khaimah and Fujairah.

In 2009, the UAE population was estimated at 6 million, of which fewer than $20 \%$ were UAE nationals or Emiratis [11]. The country's net migration rate stands at 22.98 per 1,000 inhabitants, the World's highest. The population of the UAE has a skewed sex distribution consisting of more than twice as many males as females, and in the 15-65 years age group it has a male:female ratio of 2.743. The UAE's gender imbalance is only surpassed by other Arab countries in the Gulf region.

The methodology and objectives of the ECRHS have been described previously [12]. Summarising, a random sample of the population aged 20-44 years is contacted and requested to complete a short screening questionnaire on respiratory symptoms. In a second phase of the study a $20 \%$ random sub-sample of the sample population and all remaining subjects reporting respiratory symptoms in the screening questionnaire and not yet included in the random sub-sample are asked to complete a long questionnaire and other tests.

\section{Population sampling and ethics}

We included in the study male and female individuals of all ages in the seven emirates of the UAE. The sample size was calculated with a precision level of $3 \%$, population size of 6 million, 95\% Confidence Interval, and estimated asthma prevalence of $13 \%$. Overall, 1,225 individuals were selected according to the following predetermined sampling quotas by gender $(66.5 \%$ males and $33.5 \%$ females); age (26.1\% 0-19 year old, $72 \%$ 20-59 year old and $1.9 \% \geq 60$ year old); residency status $(20.1 \%$ nationals and $79.8 \%$ expatriates); and geography within the UAE (34.1\% Abu Dhabi, 32.2\% Dubai, 19.3\% Sharjah, 5\% Ajman, 1.2\% Umm Al-Quwain, 5.1\% Ras Al-Khaimah, and $3.1 \%$ Fujairah). Given the absence of usable census information in the UAE, interviews were conducted in public locations across the seven emirates including town centers, malls, outside mosques, and industrial areas from late January 2010 to early March 2010. Apart from the inability to signing the informed consent, there were no exclusion criteria in this research. All participants were informed of the voluntary nature of this research and signed an informed written consent. This research protocol was approved by Clinical Research Ethics Authority of Dubai, UAE.

\section{Questionnaire}

The English versions of the screening and long ECRHS questionnaires [12] were translated to Arabic, and participants were interviewed in a side-by-side bilingual version, to assess the presence of respiratory symptoms, other conditions, smoking, and treatments. As the interest was to use the ECRHS screening questionnaire in the most sensitive way as possible, any individual was considered symptomatic of asthma if he/she answered YES to any of the following questions: "Have you had wheezing or whistling in your chest at any time in the last 12 months?", or "Have you been coughing constantly for more than 3 weeks in any time in your life?", or "Have you had an attack of asthma in the last 12 months?", or "Do you have any nasal allergies including hay fever?". In addition any smoker or anyone answering YES to $50 \%$ of the eight questions of the ECRHS screening questionnaire was qualified for the survey.

All interviews were administered by an interviewer, and participants had the option to answer questions in the language they were more comfortable with, either Arabic or English. Results of the ECRHS screening questionnaire only are presented in this report.

\section{Statistical analysis}

Data are presented as mean and standard deviation (SD) for continuous variables, or percentage for qualitative variables, as appropriate. Differences within groups were compared with analysis of variance (ANOVA) for continuous variables, and $\mathrm{Chi}^{2}$ for categorical variables. The prevalence of asthma symptoms and their 95\% confidence intervals (95\% C.I.) was estimated for all participants, and by gender and age bands. Due to the sampling quotas by age, and also to compare directly with ECRHS centers, the most relevant results are also presented for participants 20-44 years, and younger and older ages. A $p<0.05$ was considered statistically significant.

\section{Results}

The total number of respondents interviewed with sociodemographic data was 1,220 (Figure 1), of which 


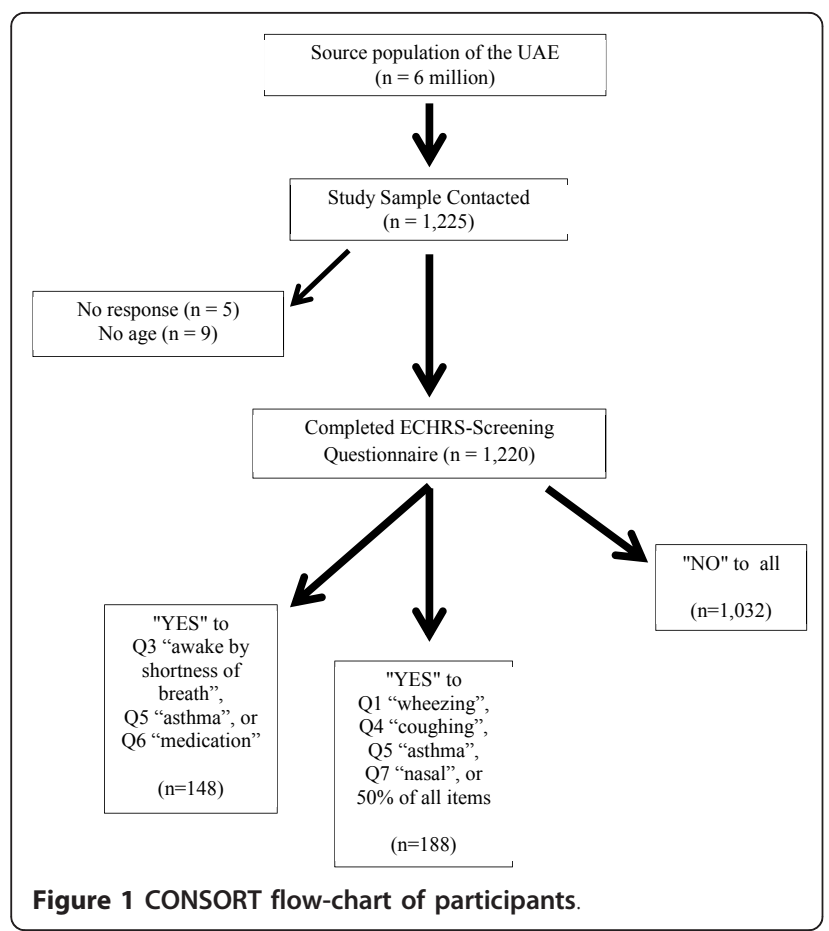

$63.2 \%$ were male, and $20.1 \%$ were UAE Nationals, with a mean (SD) age of 32.9 (14.1) years, all according to the above mentioned quotas. In detail, sampling percentages of participants per Emirate was 34.1\% Abu Dhabi, 32.2\% Dubai, 19.3\% Sharjah, 5.0\% Ajman, 1.3\% Umm AlQuwain, 1\% Ras Al-Khaimah, and 3.1\% Fujairah.
Results by gender and age are presented for participants 20-44 years, younger and older ages (Table 1).

Prevalence of individual respiratory symptoms according to the ECRHS screening questionnaire in all participants were ranging from 8 to $10 \%$, except for, lower for nasal allergies (6.8\%) (Table 2). However, when stratified by age band, it can be seen that in participants younger than 20 years, as well as those older than 44 years, prevalence of nearly all symptoms are $10 \%$ or higher, while those participants 20-44 years presented lower prevalence in all symptoms $(p<0.05)$.

We explored the male:female ratio of reported wheezing and of asthma attacks and its treatment by age (Figure 2). The classical inversion of the male:female ratio in adolescence was not observed; in girls 5-15 years wheezing and asthma attacks were more common than in boys, while prevalence of these symptoms were evenly reported up to the age of 60 years and older. Surprisingly, reported asthma treatment showed no gender ratio and was unchanged in all age bands, namely $9.3 \%$ in participants younger than 20 years, $6.6 \%$ in participants $20-44$ years, and $10.3 \%$ in participants older than 44 years (Table 2).

These respiratory symptoms according to the ECRHS screening questionnaire are next presented in participants 20-44 year, by gender (Table 3 ). It can be seen that all symptoms were reported more frequently in female than male, differences being statistically significant only for "Woken up by an attack of coughing" and for "Nasal allergies (including hay fever)" $(p<0.05)$.

Table 1 Demographic characteristics of participants, by age band

\begin{tabular}{|c|c|c|c|c|}
\hline Variable & $\begin{array}{c}19 \text { yr or less } \\
n=237 \\
(19.4 \%)\end{array}$ & $\begin{array}{c}20 \text { to } 44 \mathrm{yr} \\
\mathrm{n}=702 \\
(57.5 \%)\end{array}$ & $\begin{array}{c}45 \text { yr or more } \\
n=281 \\
(23.0 \%)\end{array}$ & $\begin{array}{c}\text { ALL } \\
\mathrm{n}=1220\end{array}$ \\
\hline Male gender, n (\%) & $139(58.6 \%)$ & $440(62.7 \%)$ & $192(68.3 \%)$ & $771(63.2 \%)$ \\
\hline Age in years, mean (SD) & $13.8(4.9)$ & $31.6(7.0)$ & $52.3(5.5)$ & $32.9(14.1)$ \\
\hline
\end{tabular}

Table 2 Symptoms according to the ECRHS screening questionnaire in participants, by age band

\begin{tabular}{|c|c|c|c|c|}
\hline $\begin{array}{l}\text { ECRHS screening questionnaire symptoms within the last } 12 \text { months, } \\
\text { n (\%) }\end{array}$ & $\begin{array}{c}19 \text { yr or less } \\
n=237 \\
(19.4 \%)\end{array}$ & $\begin{array}{c}20 \text { to } 44 \mathrm{yr} \\
\mathrm{n}=702 \\
(57.5 \%)\end{array}$ & $\begin{array}{c}45 \text { yr or more } \\
n=281 \\
(23.0 \%)\end{array}$ & $\begin{array}{c}\text { ALL } \\
n=1220\end{array}$ \\
\hline Wheezing/whistling & $31(13.1 \%)$ & $57(8,1 \%)$ & $34(12.1 \%)$ & $122(10.0 \%)$ \\
\hline Wheezing with breathlessness & $27(11.4 \%)$ & $50(7.1 \%)$ & $32(11.4 \%)$ & $109(8.9 \%)$ \\
\hline Wheezing without a cold & $24(10.1 \%)$ & $43(6.1 \%)$ & $31(11.0 \%)$ & $98(8.0 \%)$ \\
\hline Woken up with chest tightness & $32(13.5 \%)$ & $53(7.5 \%)$ & $34(12.1 \%)$ & $119(9.8 \%)$ \\
\hline Woken up by shortness of breath & $30(12.7 \%)$ & $51(7.3 \%)$ & $30(10.7 \%)$ & $111(9.1 \%)$ \\
\hline Woken up by an attack of coughing & $30(14.8 \%)$ & $59(8.4 \%)$ & $33(11.7 \%)$ & $127(10.4 \%)$ \\
\hline Attack of asthma & $28(11.8 \%)$ & $42(6.0 \%)$ & $27(9.6 \%)$ & $97(8.0 \%)$ \\
\hline Currently taking asthma medications & $22(9.3 \%)$ & $46(6.6 \%)$ & $29(10.3 \%)$ & $97(8.0 \%)$ \\
\hline Nasal allergies (including hay fever) & $22(9.3 \%)$ & $46(6.6 \%)$ & $15(5.3 \%)$ & 83 (6.8\%) \\
\hline
\end{tabular}


Overall, there were 184 (15.4\%, 95\% C.I. 13.5 - 17.5) participants who fulfilled our screening criteria for asthma (Figure 1). These asthmatics were more frequently male $(56.5 \%)$ but there were no significant differences by age in male versus female asthmatics (Table 4). As per the results in the general population, there were neither clinical nor statistical differences in the distribution of individual respiratory symptoms by

A)

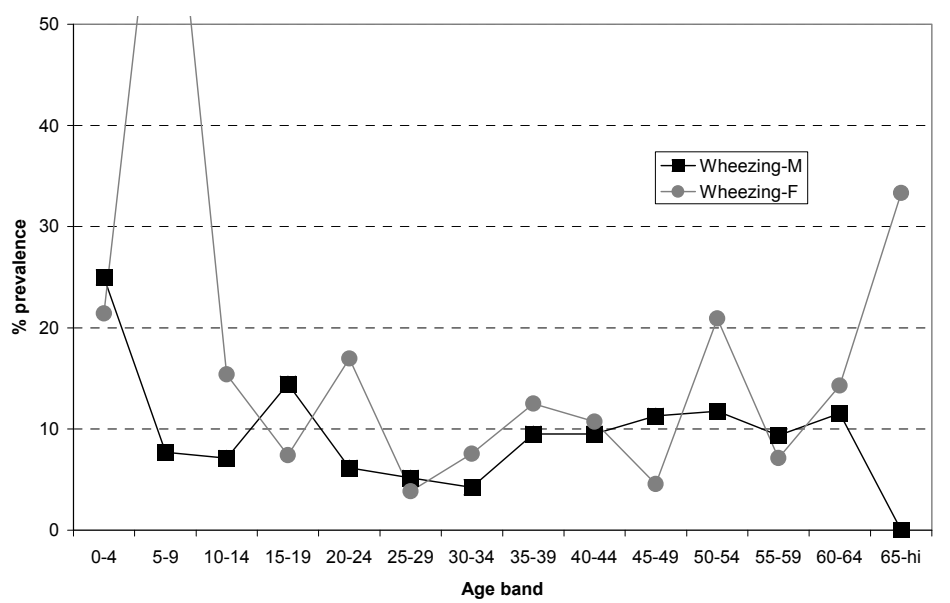

B)

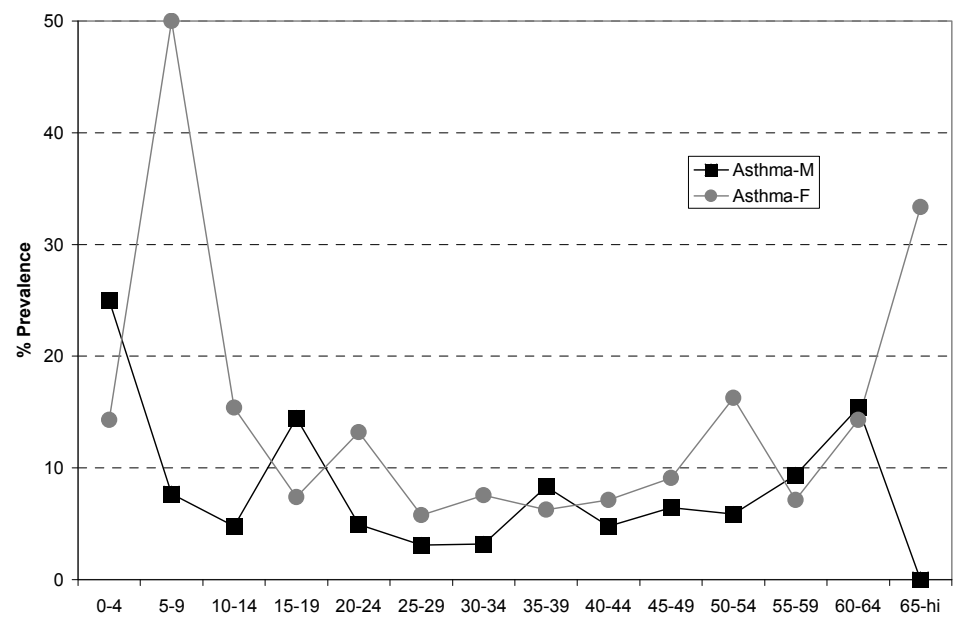

Age

C)

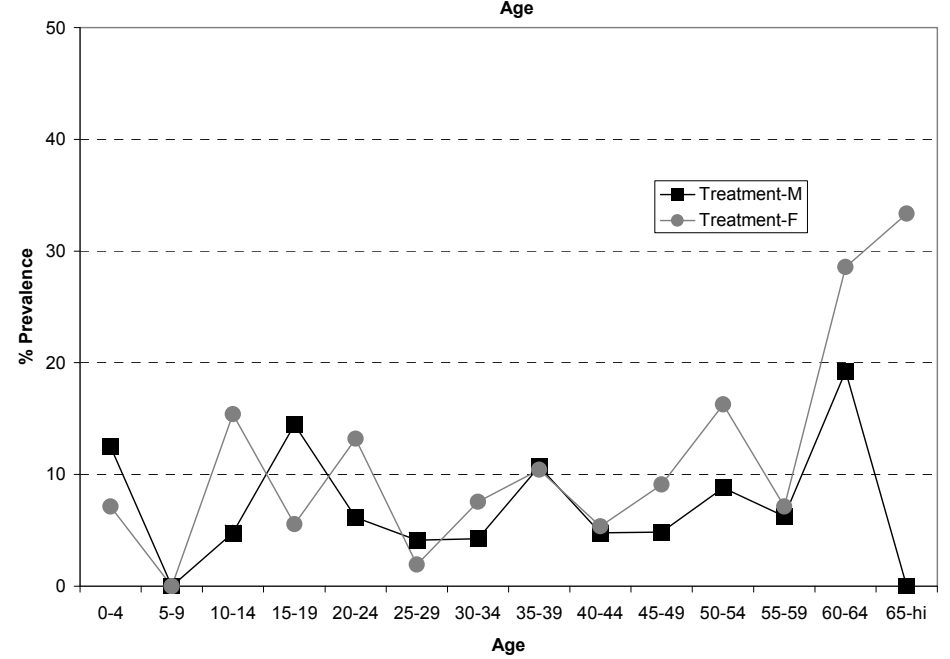

Figure 2 Prevalence of wheezing (A), asthma attack (B) and asthma medication (C) by age, in male and female. 
Table 3 Symptoms according to the ECRHS screening questionnaire in participants 20-44 yr, by gender

\begin{tabular}{lccc}
\hline ECRHS screening questionnaire symptoms within the last $\mathbf{1 2}$ months, $\mathbf{n}(\%)$ & $\begin{array}{c}\mathbf{2 0} \text { to } \mathbf{4 4} \text { yr } \\
\text { male } \\
\text { (n = 440) }\end{array}$ & $\begin{array}{c}\mathbf{2 0} \text { to } \mathbf{4 4} \text { yr } \\
\text { female } \\
\text { (n = 262) }\end{array}$ & $\begin{array}{c}\boldsymbol{p} \\
27(10.3 \%)\end{array}$ \\
\hline Wheezing/whistling & $30(6.8 \%)$ & 0.069 \\
$\quad$ Wheezing with breathlessness & $26(5.9 \%)$ & $24(9.2 \%)$ & 0.253 \\
$\quad$ Wheezzing without a cold & $23(5.2 \%)$ & $20(7.6 \%)$ & 0.255 \\
\hline Woken up with chest tightness & $28(6.4 \%)$ & $25(9.5 \%)$ \\
\hline Woken up by shortness of breath & $31(7.0 \%)$ & $20(7.6 \%)$ & 0.080 \\
\hline Woken up by an attack of coughing & $29(6.6 \%)$ & $30(11.5 \%)$ & 0.440 \\
\hline Attack of asthma & $21(4.8 \%)$ & $21(8.0 \%)$ & $0.034^{*}$ \\
\hline Currently taking asthma medications & $26(5.9 \%)$ & $20(7.6 \%)$ & 0.230 \\
\hline Nasal allergies (including hay fever) & $21(4.8 \%)$ & $25(9.5 \%)$ & $\mathbf{0 . 0 1 1 *}$ \\
\hline
\end{tabular}

"** Significant $p$-value

gender in these asthmatics, except for "Wheezing without a cold" $(p<0.05)$ (Table 4$)$.

For consistency with ECRHS sampling methodology, results in those participants responding YES to the following three questions: "Have you been woken by an attack of shortness of breath at any time in the last 12 months?", or "Have you had an attack of asthma in the last 12 months?", or "Are you currently taking any medicine (including inhalers, aerosols or tablets) for asthma?" are presented in Table 5. There were 146 (12.1\%, 95\% C.I 10.4 - 14.1) participants who fulfilled the ECRHS asthma definition in all ages. Specifically, the ECRHS asthma prevalence in those 702 participants with $20-44$ years was $9.8 \%$ (95\% C.I. 7.8 - 12.2), that is in males $8.6 \%$ (95\% C.I. 6.2 - 11.7) and in females $11.8 \%$ (95\% C.I. 8.2 - 16.4) participating.
Compared to results in Table 4, these ECRHS-definition asthmatics were also more frequently male (57.5\%), but again there were no significant differences by age in male versus female ECRHS-definition asthmatics. The distribution of individual respiratory symptoms by gender in these asthmatics were evenly distributed, again except for "Wheezing without a cold" $(p<0.05)$ (Table 5)

Finally, an approximation to asthma incidence is presented in Figure 3, from birth to age 50 years. As expected, the reported age of the first attack of asthma occurred more frequently in childhood and adolescence, but in males there was a peak in asthma incidence (10\%) after the age of 20 years, while in females there was another peak in asthma incidence (7\%) after the age of 25 years.

Table 4 Characteristics of those responding "YES" to Q1 "wheezing", Q4 "coughing", Q5 "asthma", or Q7 "nasal" according to the ECRHS screening questionnaire $(n=184)$

\begin{tabular}{|c|c|c|c|c|}
\hline & $\begin{array}{c}\text { male } \\
(n=104)\end{array}$ & $\begin{array}{c}\text { female } \\
(n=80)\end{array}$ & $\begin{array}{c}\text { ALL } \\
\mathrm{n}=184\end{array}$ & $p$ \\
\hline Age in years, mean (SD) & $34.0(15.4)$ & $31.3(15.7)$ & $32.8(15.5)$ & 0.247 \\
\hline Age band, n (\%) & & & & 0.309 \\
\hline - 19 yr or less & $27(26.0 \%)$ & $18(22.5 \%)$ & $45(24.5 \%)$ & \\
\hline - 20 to $44 \mathrm{yr}$ & $47(45.2 \%)$ & $45(56.3 \%)$ & $92(50.0 \%)$ & \\
\hline - 45 yr or more & $30(28.8 \%)$ & $17(21.3 \%)$ & $47(25.5 \%)$ & \\
\hline \multicolumn{5}{|c|}{ ECRHS screening questionnaire symptoms within the last 12 months, $n(\%)$} \\
\hline Wheezing/whistling & $68(65.4 \%)$ & $57(67.9 \%)$ & $125(66.5 \%)$ & 0.758 \\
\hline Wheezing with breathlessness & $60(57.7 \%)$ & $51(60.7 \%)$ & $111(59.0 \%)$ & 0.916 \\
\hline Wheezzing without a cold & $59(56.7 \%)$ & 39 (46.4\%) & $98(52.1 \%)$ & $0.043^{*}$ \\
\hline Woken up with chest tightness & $57(54.8 \%)$ & $44(52.4 \%)$ & $101(53.7 \%)$ & 0.770 \\
\hline Woken up by shortness of breath & $59(56.7 \%)$ & $42(50.0 \%)$ & $101(53.7 \%)$ & 0.380 \\
\hline Woken up by an attack of coughing & $70(67.3 \%)$ & $60(71.4 \%)$ & $130(69.1 \%)$ & 0.634 \\
\hline Attack of asthma & $52(50.0 \%)$ & $47(56.0 \%)$ & $99(52.7 \%)$ & 0.464 \\
\hline Currently taking asthma medications & $54(51.9 \%)$ & $41(48.8 \%)$ & $95(50.5 \%)$ & 0.769 \\
\hline Nasal allergies (including hay fever) & $45(43.3 \%)$ & $40(47.6 \%)$ & $85(45.2 \%)$ & 0.559 \\
\hline
\end{tabular}

"** Significant $p$-value 
Table 5 Characteristics of those responding "YES" to Q3 "shortness of breath", Q5 "asthma", or Q6 "treatment of asthma", according to the ECRHS main questionnaire $(n=146)$

\begin{tabular}{|c|c|c|c|c|}
\hline & $\begin{array}{c}\text { male } \\
(n=84)\end{array}$ & $\begin{array}{c}\text { female } \\
(n=62)\end{array}$ & $\begin{array}{c}\text { ALL } \\
n=146\end{array}$ & $p$ \\
\hline Age in years, mean (SD) & $30.8(16.7)$ & $33.9(16.2)$ & $32.6(16.4)$ & 0.263 \\
\hline Age band, $\mathrm{n}(\%)$ & & & & 0.711 \\
\hline - 19 yr or less & $22(26.2 \%)$ & $17(24.4 \%)$ & $39(26.7 \%)$ & \\
\hline - 20 to $44 \mathrm{yr}$ & $38(45.2 \%)$ & $31(50.0 \%)$ & $69(47.3 \%)$ & \\
\hline - 45 yr or more & $24(28.6 \%)$ & $14(22.6 \%)$ & $38(26.0 \%)$ & \\
\hline \multicolumn{5}{|c|}{ ECRHS screening questionnaire symptoms within the last 12 months, $n$ (\%) } \\
\hline Wheezing/whistling & $59(70.2 \%)$ & $49(76.6 \%)$ & $108(73.0 \%)$ & 0.457 \\
\hline Wheezing with breathlessness & $53(63.1 \%)$ & $45(70.3 \%)$ & $98(66.2 \%)$ & 0.649 \\
\hline Wheezzing without a cold & $52(61.9 \%)$ & $34(53.1 \%)$ & $86(58.1 \%)$ & $0.037^{*}$ \\
\hline Woken up with chest tightness & $56(66.7 \%)$ & $38(59.4 \%)$ & $94(63.5 \%)$ & 0.392 \\
\hline Woken up by shortness of breath & $67(79.8 \%)$ & $44(68.8 \%)$ & $111(75.0 \%)$ & 0.131 \\
\hline Woken up by an attack of coughing & $54(64.3 \%)$ & $44(68.5 \%)$ & $98(66.2 \%)$ & 0.603 \\
\hline Attack of asthma & $52(61.9 \%)$ & $47(73.4 \%)$ & $99(66.9 \%)$ & 0.161 \\
\hline Currently taking asthma medications & $56(66.7 \%)$ & $42(65.6 \%)$ & $98(66.2 \%)$ & 1.000 \\
\hline Nasal allergies (including hay fever) & $29(34.5 \%)$ & $27(42.2 \%)$ & $56(37.8 \%)$ & 0.394 \\
\hline
\end{tabular}

"**" Significant $p$-value

\section{Discussion}

We report in here the first population study assessing the distribution of adult asthma in the UAE. By using

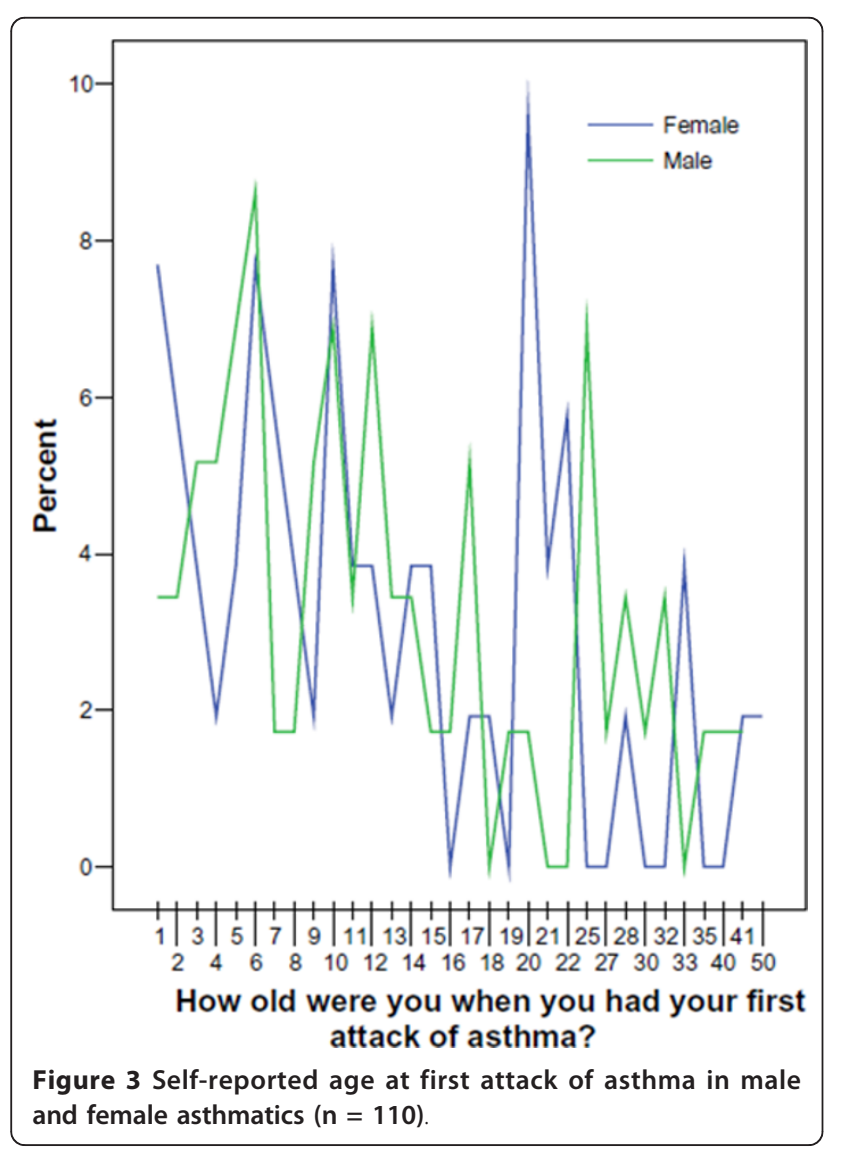

standard ECRHS questionnaires and tools, we determined that the prevalence of asthma (see Methods for definition) is at least $9.8 \%$ in young adults $20-44$ years, and participating women reported more individual respiratory symptoms than men. As previously reviewed, only our national ISAAC center reported standard data on asthma in the UAE previously, but adult asthma information was yet unavailable. Recently, Alsowaidi et al. reported indirectly that in a randomly selected, agestratified cohort of adolescent school children and their caretakers in the UAE, with a median age of 30 years (range 8 - 93 years), a $7.3 \%$ prevalence of comorbid allergic rhinitis asthma, lower in immigrants and with increasing age [13].

Our group recently participated in an international endeavor to explore the insights and realities of already diagnosed and treated asthmatics within the Gulf region [14], and results are also available for the UAE only [15]. Similar to asthmatics in other regions, it was concluded from surveying 200 asthmatics in the UAE that asthma burden and uncontrolled asthma were frequent, with $52.8 \%$ of the children and $17.1 \%$ of the adults missing school and work due to asthma in the past year, respectively. The percentage of Emirati asthmatics that had emergency room visits within the past year was $27.5 \%$, and $4 \%$ were hospitalized. Only $5.5 \%$ used inhaled corticosteroids in the past year, and $47.5 \%$ were on short-acting $\beta_{2}$-agonists. Contrary to our results in here on asthma symptoms, $85 \%$ of participating asthmatics were male.

Strengths of our research include an appropriate sample size for a prevalence study, surveying all seven 
Emirates, and the use of standard ECRHS questionnaires and methodology. However, some limitations are worth exploring. Given the reality of the UAE, with so many expatriates and immigrants, and the absence of appropriate census, it was decided to invite randomly and survey participants in public locations, rather than a doorto-door, random-digit dialing, or other sampling procedure.

Exploring the natural history of asthma in UAE is of interest, as we detected a substantial number of female asthmatics, and an absence of the expected male:female ratio of asthma incidence, to be reverted after adolescence. The gender differences in prevalence of wheeze and asthma attack did not reach statistical significance because the true differences appear to be quite small to be significantly detected based on our sample sizes of males and females. For example, using our sample sizes, the power to detect a difference in the prevalence of asthma attack between males and females that is of the order of $6 \%$ (corresponding to the observe differences in prevalence, see Table 4 ) is only $10 \%$ while the power to detect a difference in the prevalence of asthma attack between 20-44 years old males and females that is of the order of $3 \%$ (corresponding to the observed difference, see Table 3 ) is $31 \%$. Very recently, it was reported pooling data of 48 ECRHS centers from 22 countries that there was no gender difference in asthma severity when comparing two repeat surveys completed in 1993 and 2002, but it was suggested that asthma severity might be less stable in women than in men [16]. Further research on the timing of these symptoms and perhaps a relationship with active and passive smoking patterns, and exposure to known asthma triggers and other local exposures, are worth considering.

We conclude that asthma in the study sample of the UAE population is frequent, $8.6 \%$ in male and $11.8 \%$ in female young adults $20-44$ years., and that gender differences in asthma deserve further research.

\begin{abstract}
Acknowledgements
Authors had access to the database and discussed and drafted this report with external advice from Dr JB Soriano, Spain. We thank Dr Mahmoud Fikri, Assistant Undersecretary for Preventive Medicine, and Dr Huda Al-Sowaidi, Director of Health Research Center, Ministry of Health, UAE for their support, contribution and approval in performing this study in the UAE. We thank Dr Taoufik Zoubeidi, UAE University for his statistics advice. Finally, we thank Dr D Jarvis, UK, for her invaluable suggestions on an earlier version of this manuscript. Astra Zeneca provided unconditional grant support to conduct the study. The sponsor had no influence on the design of the study or the interpretation of the results.
\end{abstract}

\section{Author details}

${ }^{1}$ Department of Pulmonary Medicine, Rashid Hospital, Dubai, United Arab Emirates. ${ }^{2}$ Department of Pediatrics, Faculty of Medicine and Health Sciences, UAE University, P.O.Box 17666 Al-Ain, United Arab Emirates. ${ }^{3}$ Department of Family \& Community Medicine, Sharjah University, Sharjah, United Arab Emirates. ${ }^{4}$ Allergy and Rhinology, Nippon Medical School,
Tokyo, Japan. ${ }^{5}$ Department of Otorhinolaryngology, Al-Baraha Hospital, Dubai, United Arab Emirates. ${ }^{6}$ Chief Medical Officer, Shaikh Khalifa Medical City, Abu Dhabi, United Arab Emirates.

\section{Authors' contributions}

BHM have made substantial contributions to conception and design, acquisition of data, analysis and interpretation of data and drafting the manuscript and revising it critically for important intellectual content. SAH have made substantial contributions to analysis and interpretation of data, drafting the manuscript, critical revision for important intellectual content, and rewriting the manuscript according to the reviewers opinions. MR and AA have made substantial contributions to conception of the study, acquisition of data, and have given their final approval of the version to be published. NS have made substantial contributions to analysis and interpretation of data, and have given final approval of the version to be published. RP and ACM have made substantial contributions to conception and design, analysis and interpretation of data and drafting the manuscript, and have given final approval of the version to be published. All authors read and approved the final manuscript.

\section{Competing interests}

The authors declare that they have no competing interests.

Received: 24 July 2011 Accepted: 16 February 2012

Published: 16 February 2012

\section{References}

1. Moore WC, Pascual RM: Update in asthma 2009. Am J Respir Crit Care Med 2010, 181:1181-1187.

2. Diaz-Guzman E, Mannino DM: Airway obstructive diseases in older adults: from detection to treatment. J Allergy Clin Immunol 2010, 126:702-709.

3. Gibson PG, McDonald VM, Marks GB: Asthma in older adults. Lancet 2010, 376:803-813.

4. Mantzouranis EC: Taking your child's breath away-the extension of asthma's global reach. N Engl J Med 2008, 358:1211-1213.

5. Global Initiative for Asthma (GINA). , Documents available from www. ginasthma.org [As accessed on December 21, 2010].

6. Beasley R, Crane J, Lai CKW, Pearce N: Prevalence and aetiology of asthma. J Allergy Clin Immunol 2000, 105:S466-S472.

7. The International Study of Asthma and Allergies in Childhood (ISAAC) Steering Committee: Worldwide variations in the prevalence of asthma symptoms: the International Study of Asthma and Allergies in Childhood (ISAAC). Eur Respir J 1998, 12:315-335.

8. European Community Respiratory Health Survey: Variations in the prevalence of respiratory symptoms, self-reported asthma attacks, and use of asthma medication in the European Community Respiratory Health Survey (ECRHS). Eur Respir J 1996, 9:687-695.

9. Pearce N, Sunyer J, Cheng S, Chinn S, Björkstén B, Burr M, Keil U, Anderson HR, Burney P: Comparison of asthma prevalence in the ISAAC and the ECRHS. ISAAC Steering Committee and the European Community Respiratory Health Survey. International Study of Asthma and Allergies in Childhood. Eur Respir J 2000, 16:420-426.

10. Al-Maskari F, Bener A, Al-Kaabi A, Al-Suwaidi N, Norman N, Brebner J: Asthma and respiratory symptoms among school children in United Arab Emirates. Allerg Immunol (Paris) 2000, 32:159-163.

11. Department of Economic and Social Affairs Population Division (2009) (PDF). Expat numbers rise rapidly as UAE population touches 6 m. 2009 revision, uaeinteract.com. http://uaeinteract.com/docs/ Expat_numbers_rise_rapidly_as_UAE_population_touches_6m/37883.htm. Retrieved 2009-03-12.

12. Burney PG, Luczynska C, Chinn S, Jarvis D: The European Community Respiratory Health Survey. Eur Respir J 1994, 7:954-960.

13. Alsowaidi $S$, Abdulle A, Bernsen R, Zuberbier T: Allergic rhinitis and asthma: a large cross-sectional study in the United Arab Emirates. Int Arch Allergy Immunol 2010, 153:274-279.

14. Khadadah M, Mahboub B, Al-Busaidi NH, Sliman N, Soriano JB, Bahous J: Asthma insights and reality in the Gulf and the near East. Int I Tuberc Lung Dis 2009, 13:1015-1022.

15. Mahboub BH, Santhakumar S, Soriano JB, Pawankar R: Asthma insights and reality in the United Arab Emirates. Ann Thorac Med 2010, 5:217-221. 
16. Raherison C, Janson C, Jarvis D, Burney P, Cazzoletti L, de Marco R, Neukirch F, Leynaert B: Evolution of asthma severity in a cohort of young adults: is there any gender difference? PLoS One 2009, 4:e7146.

\section{Pre-publication history}

The pre-publication history for this paper can be accessed here: http://www.biomedcentral.com/1471-2466/12/4/prepub

doi:10.1186/1471-2466-12-4

Cite this article as: Mahboub et al.: Population prevalence of asthma and its determinants based on European Community Respiratory Health Survey in the United Arab Emirates. BMC Pulmonary Medicine 2012 12:4.

Submit your next manuscript to BioMed Central and take full advantage of:

- Convenient online submission

- Thorough peer review

- No space constraints or color figure charges

- Immediate publication on acceptance

- Inclusion in PubMed, CAS, Scopus and Google Scholar

- Research which is freely available for redistribution

Submit your manuscript at www.biomedcentral.com/submit 